\title{
Antifungal potential of tolnaftate against Candida albicans in the treatment of onychomycosis: development of nail lacquer and $e x$ vivo characterization
}

\author{
Nida Akhtar ${ }^{1}$, Soniya Sahu ${ }^{1}$, Kamla Pathak ${ }^{2 *}$ \\ ${ }^{1}$ Department of Pharmaceutics, Rajiv Academy for Pharmacy, P.O. Chhatikara, Mathura- 281001, Uttar Pradesh, India. \\ ${ }^{2}$ Department of Pharmaceutics, Pharmacy College Saifai, Uttar Pradesh University of Medical Sciences, Saifai, Etawah-206130, Uttar Pradesh, India. \\ Received: Sep 28, 2016, Revised: Oct 18, 2016, Accepted: Oct 29, 2016
}

\begin{abstract}
Onychomycosis constitutes the most common fungal infection of nail affecting finger and toe nails as well. Antifungals found to be effective in the treatment of onychomycosis. However, transport of oral antifungal agents exhibits more toxicity and requires longer treatment period. Medicated nail lacquers proved to cause lesser toxicity and required shorter treatment period. It provides not only finger/toe nail infection therapy and but also act as a protection for nails. Thus, the objective behind the present investigation was to develop nail lacquer for transungual delivery of tolnaftate. Its potency had been assessed by evaluating penetration efficiency across the bovine hoof membrane. Preliminary studies aided the optimization of thioglycolic acid as permeation enhancer $\left(\mathrm{HEF}_{\max } 0.60 \pm 0.377\right)$ and menthol as local anaesthetic. n-butanol:isopropyl alcohol with optimum drying time of $60 \mathrm{sec}$ was selected as optimum solvent system. In total nine formulations were developed based on $3^{2}$ full factorial design and characterized for drying time, non-volatile content, in vitro adhesion and permeation study. Based on highest desirability, F6 was selected as an optimized formulation and evaluated for viscosity, stability and antifungal activity. Optimized formulation exhibited optimum viscosity and stability for 1 month period. Better antifungal activity was observed against Candida albicans in comparison to the control formulation. Thus, it can be concluded from the investigation that nail lacquer could proved to be a better alternative for transungual delivery of tolnaftate.
\end{abstract}

Keywords: Bovine hoof, Candida albicans, fungal infection, onychomycosis, penetration, transungual

Pharm Biomed Res 2016; 2(3): 1-12～DOI: 10.18869/acadpub.pbr.2.3.1

\section{Introduction}

Onychomycosis, a chronic fungal infection of nail plate and nail bed is a most emerging disease of finger/toe nail nowadays. It accounts for approximately $50 \%$ of all nail diseases and is the most common disorder in adults. Treatment of onychomycosis relies widely on longduration systemic/oral antifungal therapy, which is often associated with serious side effects, drug interactions, and high recurrence rates (1). Enhanced survey on the prevalence of the disease as well as inventions of newer antifungal agents resulted in higher concern among the patients to get cure of the disease and also among medical practitioners to constitute an effective therapy. However, there has been an issue regarding the treatment which may be prescribed without prior knowledge of infection. The effectiveness of several antifungals against the fungi is not well understood and drugs are often recommended for inappropriate time periods (2).
Therefore, the treatment of onychomycosis is a challenging task as the infection is embedded within the nail (3). Antifungals are available in market in the form of cream, ointment, lotion, powder, and solutions. These formulations require high concentration of active agents to be incorporated for effective therapy because of their low efficacy. To overcome the limitations of conventional formulations there is a need of an effective system that can deliver the antifungals deep into the nail bed. However, the development of a formulation for safe and effective topical delivery in the treatment of onychomycosis is still under infancy.

Topical therapy would be an attractive alternative approach in the treatment of onychomycosis as it is found to be capable of overcoming most of the limitations of systemic administration and targeting the drug at its site of action, with minimum interactions and adverse effects. Limited permeability of the drug 
through nail plate and blood supply in the affected area might lead to sub-therapeutic concentration and can be overcome via topical application (4). Further, most of the conventionally used formulations are not specifically adapted to the nail since they are readily removed by rubbing or washing (5). To overcome these barriers, ungual delivery can be opted for the delivery of drug across the nail plate. Medicated nail lacquer formulations have been developed for effective ungual delivery of antifungals to improvise the treatment of onychomycosis. In one of our in-house research reports, potential of nail lacquer has been investigated for the treatment of psoriasis. A safe, stable, and efficacious nail lacquer of isotretinoin was formulated for effective topical clinical application. Drug targeting has been done into the nail bed in order to treat nail psoriasis (6). So, the development and evaluation of nail lacquer for its therapeutic efficacy is a well-established concept. Tolnaftate, N-methyl-n-(3-methylphenyl)-1-(naphthalene2-yloxy) methanethioamide (thiocarbamate derivative) being antifungal agents, is reported to be used in the treatment of onychomycosis. It is a BCS class IV drug and possessed low aqueous solubility $(0.00054 \mathrm{mg} / \mathrm{mL})$ and penetration (7). Low penetration potential limits its therapeutic efficacy in the treatment of nail infections that reaches deeper into the nail bed. Most of the conventionally available topical formulations like creams, ointments and gels, are not specifically adapted to the nail as they can readily undergo removal by rubbing, whipping or washing. Their impermeability at the site of application is responsible for their in-effectiveness. Various researchers have put forward their inputs in improving the penetration of tolnaftate for better efficacy and localized drug delivery (8). Topical liposomal gel was formulated by Meghana et al to improve the drug delivery had shown the limitation of drug leakage and limited entrapment efficiency (9). So, there is a need of the formulation that can overcome the barrier of poor penetration with improved therapeutic efficacy and better patient compliance. Thus, with this objective present research work was focused to devise a novel lipophilic matrix based system of tolnaftate with relevant permeation characteristics. Drug targeting was achieved to the nail bed and nail matrix by ungual delivery for the effective management of onychomycosis.

\section{Materials and methods}

Materials

Tolnaftate was obtained as a gift sample from Siemen Laboratories (Gurgaon, India). Eudragit RS 100 was procured from Evonik Roehm Pharma polymers (Essen, Germany). Thioglycolic acid (TGA) was obtained from Hi media Labs Ltd (Mumbai, India). Menthol was obtained from K. M. Chem Ltd (Mumbai, India). nbutanol was procured from SD-Fine Chem Ltd (Mumbai, India). Isopropyl alcohol was obtained from SD-Fine Chem Ltd (Mumbai, India). Poylethylene glycol 400 was obtained from Sigma Aldrich Ltd (U.S.A). Glycerol was obtained from SD-Fine Chem Ltd (Mumbai, India).

\section{Preliminary investigation}

Solvent system ratio optimization

Optimization of solvent system was done to achieve optimum drying time of nail lacquer film. Four blank formulations were prepared by varying the ratio of solvent system n-butanol and isopropyl alcohol (Table 1).

Table 1 Selection of optimum ratio of desired solvent system

\begin{tabular}{ccccc}
\hline Ingredients & S1 & S2 & S3 & S4 \\
\hline Eudragit RS 100 (\% w/v) & 10 & 10 & 10 & 10 \\
\hline PEG 400 (\% v/v) & 10 & 10 & 10 & 10 \\
\hline Glycerol (\% v/v) & 10 & 10 & 10 & 10 \\
\hline n-Butanol : Isopropyl alcohol (ml) & $1: 1$ & $1: 3$ & $1: 5$ & $1: 7$ \\
\hline Drying time (sec) & 140 & 76 & 60 & 36 \\
\hline
\end{tabular}


Concentration of Eudragit RS 100 (film forming agent), PEG 400 and glycerol (plasticizers) were kept constant. An area of $4.0 \times 4.5 \mathrm{~cm}^{2}$ was marked on glass petridish to which a uniform layer of formulation $(0.2 \mathrm{~mL})$ was applied using nail lacquer brush. Drying time of formulation(s) was determined and the solvent system that showed optimum drying time was selected (6).

\section{Hydration enhancement factor (HEF)}

Pre-weighed human nail clippings were kept in $1 \mathrm{~mL}$ aqueous solution $(5 \% \mathrm{w} / \mathrm{v})$ of each permeation enhancer in a glass vial. Simultaneously control was maintained in another glass vial in $1 \mathrm{~mL}$ deionised water. Glass vials were sealed and kept at $25 \pm 2{ }^{\circ} \mathrm{C}$ for a time period of 24 h. Nail clippings were removed from glass vials and tissue paper was used to remove any residue from the surface of nail clipping. Nail clippings were then weighed and HEF was calculated using equation 1 . On the basis of $\mathrm{HEF}$, best permeation enhancer was selected.

Hydration enhancement factor was calculated using the following equation:

$\mathrm{HEF}=\mathrm{W}_{\mathrm{P}} / \mathrm{W}_{\mathrm{W}}$

Where

$\mathrm{HEF}=$ Hydration enhancement factor calculated for $24 \mathrm{~h}$. $\mathrm{W}_{\mathrm{P}}=$ Percent weight gain of nail clipping exposed to permeation enhancer.

$\mathrm{W}_{\mathrm{W}}=$ Percent weight gain of nail clipping exposed to water (control).
For the preparation of nail lacquer $3^{2}$ full factorial design was selected. A total of nine formulations were developed (Table 2). Concentration of Eudragit RS 100 and TGA were selected as independent variables. In vitro adhesion and cumulative amount of drug permeated per unit area were taken as dependent variables. Data obtained were then subjected to Design Expert Software version 9.0.5.1 (State Ease, Inc., Minneapolis, USA) and analyzed statistically. 3D response plots were generated to estimate simultaneous influence of Eudragit RS 100 and TGA on dependent variables.

\section{Preparation of nail lacquer \\ Simple mixing}

Mixture of solvent system containing n-butanol and isopropyl alcohol (in 1:5 ratio) was prepared. Eudragit RS 100 was sonicated in one part of solvent and to another part drug $(1.0 \% \mathrm{w} / \mathrm{v})$ was dissolved by manual shaking. To the above prepared mixture, glycerol, PEG 400, thioglycolic acid and menthol were incorporated and stirred for another $30 \mathrm{~min}$. A total of nine formulations were prepared and stored until evaluation.

\section{Evaluation of nail lacquer}

Evaluation of the developed nail lacquer was carried out as per Bureau of Indian Standards, IS 9245:1994 (10).

Table $23^{2}$ full-factorial design for the preparation of tolnaftate based nail lacquer

\begin{tabular}{cccccccc}
\hline $\begin{array}{c}\text { Formulation } \\
\text { Code }\end{array}$ & $\begin{array}{c}\text { Tolnaftate } \\
(\boldsymbol{\%} \mathbf{w} / \mathbf{v})\end{array}$ & $\begin{array}{c}\text { TGA } \\
(\boldsymbol{\%} \mathbf{w} / \mathbf{v}) \\
\mathbf{X}_{\mathbf{1}}\end{array}$ & $\begin{array}{c}\text { Eudragit } \\
(\boldsymbol{\%} \mathbf{w} / \mathbf{v}) \\
\mathbf{X}_{\mathbf{2}}\end{array}$ & $\begin{array}{c}\text { PEG } \\
(\boldsymbol{\%} \mathbf{w} / \mathbf{v})\end{array}$ & $\begin{array}{c}\text { Glycerol } \\
(\boldsymbol{\%} \mathbf{w} / \mathbf{v})\end{array}$ & $\begin{array}{c}\text { Menthol } \\
(\boldsymbol{\%} \mathbf{w} / \mathbf{v})\end{array}$ & $\begin{array}{c}\text { n-butanol: } \\
\text { IPA }\end{array}$ \\
\hline F1 & 1 & $2.5(-)$ & $5(-)$ & 3 & 3 & 5 & $1: 5$ \\
\hline F2 & 1 & $5(0)$ & $5(-)$ & 3 & 3 & 5 & $1: 5$ \\
\hline F3 & 1 & $10(+)$ & $5(-)$ & 3 & 3 & 5 & $1: 5$ \\
\hline F4 & 1 & $2.5(-)$ & $10(0)$ & 3 & 3 & 5 & $1: 5$ \\
\hline F5 & 1 & $5(0)$ & $10(0)$ & 3 & 3 & 5 & $1: 5$ \\
\hline F6 & 1 & $10(+)$ & $10(0)$ & 3 & 3 & 5 & $1: 5$ \\
\hline F7 & 1 & $2.5(-)$ & $15(+)$ & 3 & 3 & 5 & $1: 5$ \\
\hline F8 & 1 & $5(0)$ & $15(+)$ & 3 & 3 & 5 & $1: 5$ \\
\hline F9 & 1 & $10(+)$ & $15(+)$ & 3 & 3 & 5 & $1: 5$ \\
\hline F10* & 1 & 7.5 & 12.5 & 3 & 3 & 5 & $1: 5$ \\
\hline
\end{tabular}

TGA: Thioglycolic acid; PEG: Polyethylene glycol; IPA: Isopropyl alcohol 


\section{Drying time}

An area of $4.0 \times 4.5 \mathrm{~cm}^{2}$ was marked on glass petridish and a film of sample was applied with the help of nail brush. Time taken for film to dry was noted down using a stopwatch. The readings were obtained in triplicate.

\section{Non-volatile content}

To the glass petridish of about $8 \mathrm{~cm}$ in diameter, accurately weighed $1.0 \pm 0.2 \mathrm{~g}$ sample was poured and spread evenly. The dish was placed in hot air oven (HICON, New Delhi, India) at $105 \pm 2{ }^{\circ} \mathrm{C}$ for $1 \mathrm{~h}$. Petridish was removed, allowed to cool and weighed. The difference in weight was calculated.

\section{Water resistance}

A film $(100 \mu \mathrm{L})$ was spread evenly on the glass plate in an area of $2 \times 2 \mathrm{~cm}^{2}$ and dried at $25 \pm 2{ }^{\circ} \mathrm{C}$. The glass plate was then weighed and immersed in water bath (HICON, New Delhi, India) maintained at $37{ }^{\circ} \mathrm{C}$. It was removed after $24 \mathrm{~h}$, wiped with tissue paper, reweighed. Difference in weight was then calculated.

\section{Blush test}

Sample $(0.2 \mathrm{~mL})$ was spread evenly over a glass plate $\left(7.2 \times 2.4 \mathrm{~cm}^{2}\right)$ and dried at room temperature. A glass beaker $(250 \mathrm{~mL})$ was filled to half its level with ordinary tap water. The plate was then immersed in the beaker so that the entire film was dipped in water and was allowed to remain as such for $24 \mathrm{~h}$. The plate was removed, wiped with tissue paper, dried at room temperature for $4 \mathrm{~h}$ and checked for the presence of any blush.

\section{In vitro adhesion}

An area of around $3.6 \times 2.4 \mathrm{~cm}^{2}$ was marked on a glass plate. A drop of sample was applied and spread with nail lacquer brush. The film was allowed to dry at $25 \pm$ $2{ }^{\circ} \mathrm{C}$ for $24 \mathrm{~h}$. Entire film was covered with cellophane tape (Cosmos Tapes and Labels Pvt. Ltd., New Delhi, India) to which pressure was applied manually by thumb. The tape was then removed briskly. Area was calculated and percent film peel off was determined.
Ex vivo permeation

Ex vivo permeation was conducted using Franz diffusion cell. Bovine hoof membrane was kept between donor and receptor compartment of diffusion cell with an effective surface area and receptor cell volume of $0.785 \mathrm{~cm}^{2}$ and $10 \mathrm{~mL}$, respectively. Nail lacquer equivalent to $6.84 \mathrm{mg}$ of the drug was placed in donor compartment of Franz diffusion cell. Samples were withdrawn $(1 \mathrm{~mL})$ via sampling port at appropriate intervals till $72 \mathrm{~h}$ and analyzed spectrophotometrically at $267 \mathrm{~nm}$ and sink conditions were maintained. Cumulative amount of drug permeated per unit area (CDP/A) across the bovine hoof was plotted against time. Flux was calculated from the slope of the linear portion of graph and compared with the target flux (6).

\section{Selection and evaluation of optimized formulation}

Optimized formulation was selected on the basis of highest desirability obtained in statistical validation of experimental design. Further, the optimized formulation was characterized for desired viscosity, in vitro antifungal activity and stability study.

\section{Viscosity}

Accurately weighted $100 \mathrm{~g}$ of the sample was placed in beaker and viscosity of optimized formulation measured by Brookfield viscometer R/S-CPS using helipath spindle \#3 at $60 \mathrm{rpm} 25^{\circ} \mathrm{C}$.

In vitro antifungal activity

Agar cup-plate method was used to determine in vitro antifungal activity against Candida albicans. Nutrient agar plates were prepared and sterilized by autoclaving at $120^{\circ} \mathrm{C}, 15$ pounds pressure for $15 \mathrm{~min}$. $30 \mathrm{~mL}$ nutrient agar media was then inoculated with fungal strain i.e. C. albicans ( $2 \mathrm{~mL}$ of inoculum to 100 $\mathrm{mL}$ of nutrient agar media). The mixture was then poured in two sterilized petriplates and three wells of 5 $\mathrm{mm}$ diameters were prepared via sterile borer in each petriplate. $0.2 \mathrm{~mL}$ each of optimized formulation, control formulation were transferred to the cups aseptically and labelled accordingly as optimized 
and control formulation. Negative and positive controls were also prepared which consist of uninoculated media and media seeded with test organism but deprived of antifungal agent, respectively. The prepared petriplates were maintained at room temperature for $2 \mathrm{~h}$ to allow the diffusion of the solutions in to the medium and then incubated at $28{ }^{\circ} \mathrm{C}$ for $48 \mathrm{~h}$ (11). The diameter of zone of inhibition surrounding each of the well was recorded using (Antibiotic zone reader, HICON, New Delhi).

\section{Stability studies}

Stability study was conducted by storing the optimized formulation at $4{ }^{\circ} \mathrm{C}$ and $25{ }^{\circ} \mathrm{C}$ for 1 month. The formulation was then evaluated for drying time, nonvolatile content, in vitro adhesion, water resistance and blush test, drug content and CDP/A.

\section{Statistical analysis and validation of experimental design}

Effect of independent variables on dependent variables was optimized by Design Expert Software version 9.0.5.1 (State Ease, Inc., Minneapolis, USA). One way ANOVA was applied and polynomial equations were generated for cumulative drug permeated per unit area and in vitro adhesion. Validation of experimental design was done using polynomial equation, for which extra design check point formulation F10* was prepared and evaluated. F10* was formulated as the average of lower and middle level of thioglycolic acid and Eudragit RS 100. The predicted value was calculated from reduced polynomial equation and compared with experimental value using paired $\mathrm{t}$-test at $95 \%$ confidence interval ( $\mathrm{p}$ $<0.05)$.

\section{Results}

Preliminary studies

Optimization of solvent system ratio

The study was conducted to select the ratio of solvent in order to formualte nail lacquer. The boiling point of n-butanol is $117.7{ }^{\circ} \mathrm{C}$ (12) and that of isopropyl alcohol was $82.4{ }^{\circ} \mathrm{C}$ (13). Thus, the evaluation was done to select the solvent system (n-butanol and isopropyl alcohol) ratio that can display optimum drying time so that rate of evaporation is neither too slow nor too fast. Maximum drying time of $140 \mathrm{sec}$ was obtained with S1 (Table 1) consisting of highest volume of n-butanol. This was above the specified drying time of 1-2 min for a nail lacquer to form a film (14). While minimum drying time of $36 \mathrm{sec}$ was observed with S4 containing least volume of n-butanol and highest volume of isopropyl alcohol. Drying time was found to be decreased with an increased concentration of isopropyl alcohol and lesser concentration of n-butanol to make a total volume of 10 $\mathrm{mL}$. Furthermore, solvent system ratio with optimum drying time of $60 \mathrm{sec}$ was selected for the preparation of nail lacquer.

\section{Hydration enhancement factor}

Hydration enhancement factor was determined for the selection of permeation enhancer that will affect the permeation of drug across the nail plate when integrated in nail lacquer. It was observed that when used in concentration of $5 \% \mathrm{w} / \mathrm{v}$, increase in the time of exhibition of hydration of nail clippings was observed. HEF of transungual permeation enhancers has a direct relationship with their transungual drug permeation enhancement efficiency. Nail weight gradually increased till $15 \mathrm{~h}$ beyond which no weight gain was noted suggesting the saturation of hydration. Time period for experimental purpose $(24 \mathrm{~h})$ was demonstrated. Use of the permeation enhancer can cause hydration of human nail clipping and regulate the hydration enhancement factor. A total of five permeation enhancers were screened for determination of HEF, and permeation enhancer had different mechanism of action by which it disturbs the structure of nail. Keratolytic agents like urea soften the nail plate and also cause damage to the nail plate surface (15). Surfactants like sodium lauryl sulphate, tween 20, reduce the surface tension resulting in enhanced wetting and thus increased permeability through water filled pores (16). Permeation enhancer affected the hydration capacity which changes the structure or affect physiochemical properties of nail. Accordingly, the $\mathrm{HEF}$ of various permeation enhancers varied widely in the range of 2.03 to 0.96 . HEF was found to be maximum (2.03) for nail clipping drenched in solution of thioglycolic acid. Thioglycolic acid is a thiol compound that breaks disulphide bonds which can significantly disturb the structure of nail plate and result 
in formation of new pores. As large number of disulphide bonds is present in nail keratin thus, nails were more susceptible to thioglycolic acid as compared to other permeation enhancer (17). This, guided the selection of thioglycolic acid.

\section{Preparation and evaluation of nail lacquer}

Nail lacquers were formulated using $3^{2}$ factorial design and evaluated for drying time, non-volatile content, water resistance, blush test, in vitro adhesion, \%CDP and antifungal activity.

\section{Drying time}

Drying time of nail lacquer varied from $53.90 \pm 6.42$ to $80.46 \pm 0.80 \mathrm{sec}$ (Table 3.) Optimum drying time in case of nail lacquer was found to be 1-2 min (7). All the formulations (F1-F9) showed the drying time in the desired range. It was found to be least for formulation F1 prepared with lower levels of TGA and Eudragit RS 100. Maximum drying time was observed in formulation F9 $(80.46 \pm 0.80 \mathrm{sec})$ and minimum in F1 formulation $(53.90 \pm 6.42 \mathrm{sec})$.

\section{Non-volatile content}

Non-volatile content for all the nine formulations was found to be in range of $91.66 \pm 0.33-98.53 \pm 0.36 \%$.
Highest value of non-volatile content was observed in formulation F2 and minimum in case of formulation F1.

\section{Water resistance}

Nail lacquer resistance towards water was evaluated by water resistance test by calculating the weight loss occurred after immersion in water. The amount of water absorbed by the nail lacquer film after keeping in water for 24 hours was found to be less. Thus, all the formulation exhibited high water resistance

\section{Blush test}

All the formulations passed the blush test. Absence of whitishness approved the blush test. Further, none of the formulation exhibited any blistering or peeling off.

\section{In vitro adhesion}

In vitro adhesion was found to be in range of $2.78 \pm$ 0.64 to $9.28 \pm 0.24$. F9 formulation consisting of highest concentration of Eudragit RS 100 showed minimum adhesion of $2.78 \pm 0.64 \%$ film peel off while highest film peel off $(9.28 \pm 0.24 \%)$ in case of $\mathrm{F} 1$ was a result of low level of Eudragit RS 100. Overall, less than $10 \%$ of the film peel off from all the formulations (Table 3) suggested acceptable adhesion (10).

Table 3 Characterization of nail lacquer based formulations of tolnaftate (F1-F9).

\begin{tabular}{cccccccc}
\hline $\begin{array}{c}\text { Drying time } \\
(\mathbf{S e c})\end{array}$ & $\begin{array}{c}\text { Non-volatile } \\
\text { content }(\boldsymbol{\%})\end{array}$ & $\begin{array}{c}\text { Water } \\
\text { resistance }\end{array}$ & $\begin{array}{c}\text { Adhesion } \\
(\boldsymbol{\%})\end{array}$ & $\begin{array}{c}\text { Blush } \\
\text { test }\end{array}$ & \%CDP & $\begin{array}{c}\text { Flux } \\
\left(\boldsymbol{\mu g} / \mathbf{c m}^{2} / \mathbf{h}\right)\end{array}$ & Desirability \\
\hline $53.90 \pm 6.42$ & $91.66 \pm 0.33$ & High & $9.28 \pm 0.24$ & Pass & $57.59 \pm 1.75$ & $0.07 \pm 1.12$ & 0.05 \\
\hline $63.31 \pm 4.68$ & $99.91 \pm 0.49$ & High & $8.33 \pm 0.51$ & Pass & $64.75 \pm 1.63$ & $0.15 \pm 0.95$ & 0.17 \\
\hline $65.42 \pm 1.46$ & $99.90 \pm 0.62$ & High & $6.66 \pm 0.42$ & Pass & $75.60 \pm 1.97$ & $0.11 \pm 1.09$ & 0.34 \\
\hline $69.26 \pm 6.00$ & $99.90 \pm 0.21$ & High & $5.59 \pm 0.66$ & Pass & $55.33 \pm 1.21$ & $0.16 \pm 1.32$ & 0.42 \\
\hline $70.24 \pm 5.62$ & $98.39 \pm 0.71$ & High & $5.12 \pm 0.28$ & Pass & $62.49 \pm 0.91$ & $0.12 \pm 0.99$ & 0.60 \\
\hline $72.14 \pm 4.87$ & $98.87 \pm 0.57$ & High & $4.33 \pm 0.35$ & Pass & $72.90 \pm 1.62$ & $0.12 \pm 1.43$ & 0.85 \\
\hline $77.80 \pm 1.93$ & $98.28 \pm 0.68$ & High & $4.10 \pm 0.47$ & Pass & $46.74 \pm 2.74$ & $0.15 \pm 0.96$ & 0.00 \\
\hline $78.30 \pm 2.82$ & $98.27 \pm 0.45$ & High & $3.60 \pm 0.56$ & Pass & $53.76 \pm 0.61$ & $0.12 \pm 1.01$ & 0.48 \\
\hline $80.46 \pm 0.80$ & $98.53 \pm 0.36$ & High & $2.78 \pm 0.64$ & Pass & $67.14 \pm 1.85$ & $0.11 \pm 1.37$ & 0.82 \\
\hline
\end{tabular}




\section{Ex vivo permeation}

Percent cumulative drug permeated was found to be $46.74 \pm 2.74-75.6 \pm 1.97$ for formulation F1- F9 (Table 3). Highest \%CDP of $75.60 \pm 1.97$ was observed in formulation F3 and lowest in formulation F7 (\%CDP $46.74 \pm 2.74$ ) (Figure 1). Target flux in case of topical drug delivery was determined by taking $60 \%$ of the target flux to achieve Css, where, Css is the drug concentration in plasma at steady state (18). Css of tolnafate was calculated as $0.087 \mu \mathrm{g} / \mathrm{cm}^{2} / \mathrm{h}$. The flux of the formulations was determined from the slopes of permeation profiles.
Flux of formulations F1- F9 varied with the minimum value $0.075 \pm 1.12 \mu \mathrm{g} / \mathrm{cm}^{2} / \mathrm{h}(\mathrm{F} 1)$ and maximum value $0.166 \pm 1.32 \mu \mathrm{g} / \mathrm{cm}^{2} / \mathrm{h}$ (F4). To elucidate the release mechanism, ex vivo permeation data was fitted to zero order, first order, Higuchi model, Hixson-crowell and Korsemeyer-peppas model. The data best fitted to the Higuchi model $\left(\mathrm{r}^{2} 0.9488-0.9492\right)$ that indicated the drug permeation to be diffusion controlled (Table 4). Further, to characterise the exact mechanism of drug permeation from polymeric film of nail lacquer, diffusion exponent (n) was calculated for all the formulations and was between 0.2812 and 0.3910 thus

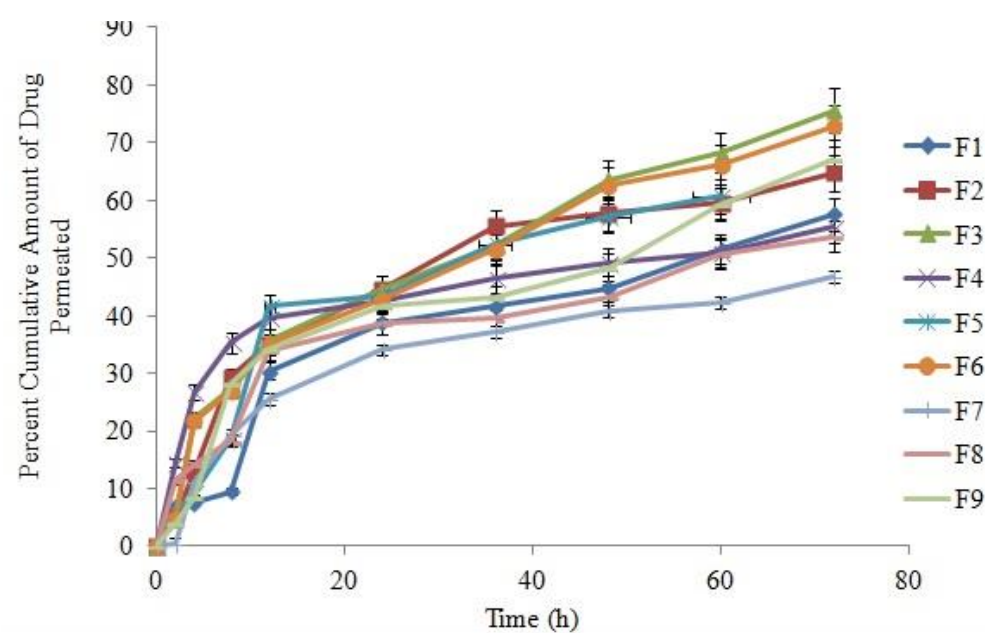

Figure 1 Percentage cumulative drug permeation profile of F1-F9 formulation

Table 4 Model fitting and coefficient of correlation describing independent variables and dependent response

\begin{tabular}{|c|c|c|c|c|c|}
\hline \multirow{2}{*}{$\begin{array}{c}\text { Formulation } \\
\text { code }\end{array}$} & \multirow[b]{2}{*}{ Zero order } & \multirow[b]{2}{*}{ First order } & \multicolumn{3}{|c|}{ Regression Coefficient $\left(\mathbf{r}^{2}\right)$} \\
\hline & & & Higuchi & $\begin{array}{l}\text { Hixson- } \\
\text { crowell }\end{array}$ & $\begin{array}{c}\text { Korsemeyer } \\
\text { peppas }\end{array}$ \\
\hline F1 & 0.8745 & 0.9271 & 0.9968 & 0.9123 & 0.9488 \\
\hline $\mathrm{F} 2$ & 0.8273 & 0.9080 & 0.9549 & 0.8228 & 0.8737 \\
\hline F3 & 0.8991 & 0.9760 & 0.9827 & 0.9584 & 0.8477 \\
\hline $\mathrm{F} 4$ & 0.6775 & 0.7746 & 0.8706 & 0.7455 & 0.6612 \\
\hline F5 & 0.8174 & 0.8895 & 0.9339 & 0.8656 & 0.8906 \\
\hline F6 & 0.8940 & 0.9716 & 0.9813 & 0.9520 & 0.8495 \\
\hline F7 & 0.8182 & 0.8741 & 0.9452 & 0.8530 & 0.7951 \\
\hline F8 & 0.8316 & 0.8919 & 0.9513 & 0.8752 & 0.7886 \\
\hline F9 & 0.8640 & 0.9314 & 0.9492 & 0.9145 & 0.8939 \\
\hline
\end{tabular}


drug permeation from all the formulations showed Fickian diffusion $(\mathrm{n}=0.45)$. The amount of drug permeated will be therapeutically equivalent to the amount of drug release. The higher the amount of drug permeated through the nail plates more it will be available to the target site for therapeutic effect.

\section{Statistical analysis and validation of experimental design}

Effect of independent variables TGA and Eudragit RS 100 on dependent variables: (CDP/A) and in vitro adhesion (\%film peel off) were assessed statistically using Design Expert software version 9.0.5.1. The mathematical equations generated for the response parameter(s) are expressed as:

$$
\left.\% \mathrm{CDP}=12.22-4.59 \mathrm{~A}-0.89 \mathrm{~B}+2.64 \mathrm{~A}^{2} \quad \text { (Eq. } 2\right)
$$$$
\% \text { Film peel off }=62.10-5.05 A+9.33 B-2.64 A^{2}+
$$

Considering these polynomial equations, the responses can be predicted at any value of Eudragit RS 100 and TGA. \%CDP increased on simultaneously decreasing the concentration of Eudragit RS100 (Figure 2A). Similarly, in vitro adhesion also increased on simultaneously increasing the level of TGA independent variables (Figure 2B). Finally, the optimized formulation was selected on the basis of desirability. Extra design check point formulation was prepared to validate the design. From the polynomial equation the predicted value of $\% \mathrm{CDP}$ and \%film peel off was calculated as 64.13 and 10.14 , respectively. Experimental values were determined as $59.67 \%$ and $9.81 \%$, respectively.
Percent error of $4.46 \%$ and $0.33 \%$ between predicted and observed value indicates that $3^{2}$ factorial design used for the formulation of nail lacquer is validated.

\section{Selection and evaluation of optimized formulation}

The optimized formulation of nail lacquer formulation was identified as F6 on the basis of maximum desirability (0.857). Optimized formulation was then evaluated and compared with the control formulation.

\section{Viscosity and stability}

Viscosity of the optimized formulation (F6) was found to be $381.42 \pm 1.22 \mathrm{cp}$. Stability test of optimized formulation (F6) was performed. The data revealed one month stability of (F6) formulation in terms of drying time, non-volatile content, water resistance, in vitro adhesion, blush test and \% CDP (Table 5).

\section{In vitro antifungal activity}

Antifungal activity was conducted for control solution and optimized nail lacquer formulation (F6) against Candida albicans. Positive and negative controls (Figure 3A and 3B) were also compared. On comparing the zone of inhibition, it was observed that more antifungal activity was exerted by F6 as more value of inhibition zone than control formulation (F6 > CF) (Figure 3C and 3D). Zone of inhibition showed by optimized formulation was $2.83 \pm 0.86 \mathrm{~mm}$ that was found to be more than zone of inhibition showed by control formulation of tolnaftate $(1.53 \pm 0.61 \mathrm{~mm})$.

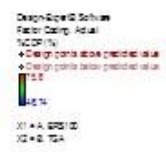

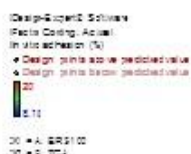

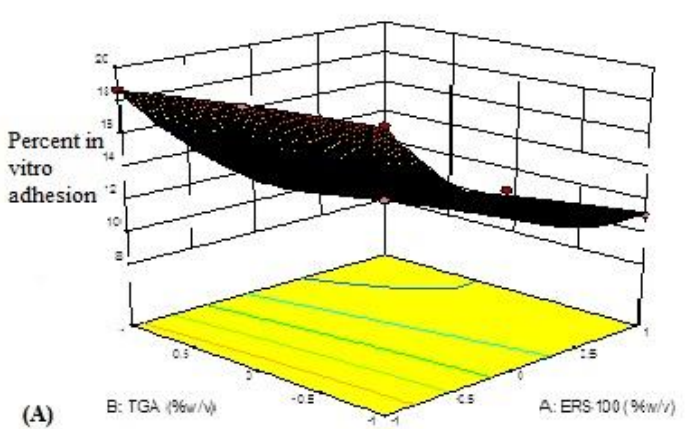

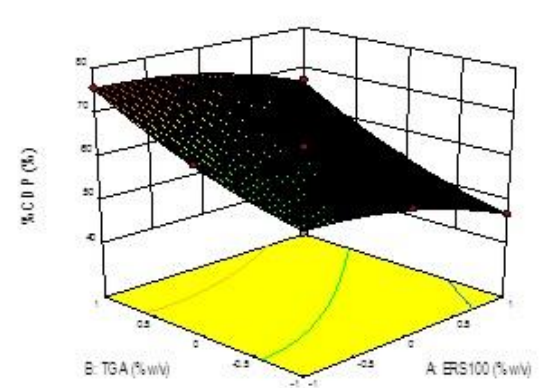

(B)

Figure 2 3D response surface plots showing the effect of independent variables (A) in vitro adhesion and (B) \% CDP. 
Figure 3 In vitro anti fungal activity of (A) Positive control (B) Negative control (C) Control formulation (D) Optimized formulation

Table 5 Stability data of optimized nail lacquer based formulation (F6)

\begin{tabular}{cccccccc}
\hline $\begin{array}{c}\text { Storage time } \\
\text { (days) }\end{array}$ & $\begin{array}{c}\text { Drying time } \\
\text { (Sec) }\end{array}$ & $\begin{array}{c}\text { Non-volatile } \\
\text { content (\%) }\end{array}$ & $\begin{array}{c}\text { Water } \\
\text { resistance }\end{array}$ & $\begin{array}{c}\text { Blush } \\
\text { test }\end{array}$ & $\begin{array}{c}\text { In vitro } \\
\text { adhesion(\%) }\end{array}$ & $\begin{array}{c}\text { Percent } \\
\text { drug } \\
\text { content }\end{array}$ & \% CDP \\
\hline 0 & $90.60 \pm 2.18$ & $94.63 \pm 0.76$ & High & Pass & $8.74 \pm 1.10$ & $86.34 \pm 1.08$ & $70.15 \pm 1.81$ \\
\hline 15 & $89.17 \pm 1.29$ & $97.88 \pm 1.39$ & High & Pass & $7.91 \pm 1.23$ & $91.87 \pm 1.14$ & $68.14 \pm 2.63$ \\
\hline 30 & $88.84 \pm 1.32$ & $95.82 \pm 1.26$ & High & Pass & $7.03 \pm 1.19$ & $81.62 \pm 1.09$ & $67.34 \pm 2.76$ \\
\hline
\end{tabular}

\section{Discussion}

Onychomycosis is defined as a fungal infection affecting nails of finger or toes resulting in thickening, discoloration, and separation from the nail bed. Transungual drug delivery defined the drug transport across the nail to gain targeted drug delivery in order to treat nail diseases (19). Transungual drug transport system is thought to be quite effective to manage nail disorders because of its better adherence, localized action, which provides minimum systemic side effects (20). Ungual therapy provides several benefits over oral/systemic drug delivery such as preparation is easy compared to oral dosage forms like tablets, and so forth. It provides improved adherence and is suitable for those who are unable to take systemic medication (20). Nail lacquers have been employed as a cosmetic in order to provide protection to the nails and to decorate the nails. Medicated nail lacquers constitute an innovative type of formulation that have been used for transungual drug delivery (21). Upon application to the nail plate, solvent evaporation takes place. The film left behind after solvent evaporation works like a drug depot. From this drug store, drug undergoes release and penetration across the nail for an optimum time period. High diffusion gradient is generated for drug permeation into the nail plate (22). Film formation on nail plate also causes reduction in water loss from the surface of nail surface into the atmosphere. Hyperhydration of the upper nail plate layers takes place, further assisting in drug diffusion. The active agent penetration can further be improvised via use of penetration enhancers like thiol compounds, hydrating agents, and keratolytic agents (23).

Nail lacquer based formulation were developed in the present investigation using $3^{2}$ factorial design. All the prepared formulations were then analyzed for drying time, non-volatile content, water resistance, blush test, 
in vitro adhesion, ex vivo permeation investigation. Drying time was considered an important evaluation parameter for developed nail lacquers. As, it was reported that very less drying time leads to poor flow of lacquer. Thus, resulting in uneven and streaky application and making the film dull. Also, the residence time of sample on nail lacquer brush will get reduced thus making the application of nail lacquer on nail plate difficult. Whereas hardening of nail lacquer and poor pick of the lacquer on brush may occur as a result of very high drying time. Therefore, the presence of optimum drying time of 1-2 min is considered to be desirable (24). From drying time analysis, it was observed that all the values were within the reported optimum range. Determination of non-volatile content gives the information about the amount of coverage that can acquired by the nail lacquer. Solvent present in the formulation gets evaporated leaving solid components behind that provides coverage to the entire nail plate (25). Non-volatile content depends upon the concentration of polymer used and was found to be directly proportional to the concentration of Eudragit. Formulation F9 exhibited maximum non-volatile content because of the presence of highest concentration of Eudragit RS 100. Nail lacquer resistance towards water was determined by water resistance test. Uptake of water followed by surface erosion from the film may lead to weight loss and it depends on the solubility of film in media (26). Eudragit RS 100 helps in the formation of water insoluble film (27) and thus none or negligible loss occurs in weight was observed. Blush test was performed to monitor the physical changes like any blistering or peeling off of nail lacquer film when exposed to water or external environment. All the formulations showed optimum lustre and retained their lustrous value even after the test. Besides all these characteristics, nail lacquer should be well adherent to the nail plate in order to form a film over the nail plate. Thus, good adhesive characteristics are required. To check this, in vitro adhesion study was carried out. Films prepared with Eudragit showed optimum adhesive properties (28). Therefore, with an increased concentration of Eudragit, the percent peel off of film was observed to get reduced. However, the effect of
TGA on the film strength was observed to be insignificant. Further, ex vivo permeation study was conducted to evaluate the permeation across the membrane for transungual drug delivery. The amount of drug permeated per unit area per unit time (flux) using bovine hoof membrane was determined in phosphate buffer, pH 7.4. Eudragit RS 100 was used as a film forming agent and release retardant for nail lacquer preparation and it exhibited a negative effect on \%CDP, when the concentration of Eudragit RS 100 increased. \%CDP was found to be increased with decreased concentration of Eudragit RS 100 and increased concentration of TGA. As Formulation F3 containing lowest concentration of Eudragit RS 100 and highest concentration of thioglycolic acid showed maximum \% CDP. Formulation F7 containing highest concentration of Eudragit RS 100 and lowest concentration of TGA showed minimum \%CDP. TGA, being a thiolic compound contain sulphydryl group (-SH) and is responsible for the cleavage of disulphide bonds present in nail keratin. The effect of thioglycolic acid was attributed to its small molecular weight and damage caused by it on the keratin network. Whereas it causes reduction in the lipid content in dorsal nail layer and thus disturbing the nail structure (29). The disulfide links are reported to be present in bovine hoof as well, thus TGA was found to be effective as permeation enhancer in transporting tolnaftate across the experimental membrane. Furthermore, target flux is considered to be an important parameter in evaluating permeation efficacy in case of formulations achieving effective permeation. Target flux is defined as the minimum flux required by the drug to undergo permeation across the semi-permeable membrane in order to gain optimum therapeutic effect. The experimental flux value(s) of all the formulations was found to be greater than required target flux indicating the capability of formulations to achieve therapeutic levels. Extra design check point formulation was developed in order to validate the design. Minute error between predicted and observed values depicted that the design has been validated. Formulation F6 was then selected as an optimized formulation and characterized for viscosity, antifungal activity and stability study. Desirable viscosity exhibited an essential 
role in impeding the drug permeation from the nail lacquer (6). Formulation F6 was found to possess optimum viscosity with stability for the period of one month. As no significant difference $(p>0.05)$ was observed in the values of drying time, non-volatile content, water resistance, in vitro adhesion, blush test and \%CDP. Further, effective antifungal activity was exhibited by the optimized formulation. As higher drug content present in the optimized nail lacquer allowed higher diffusion of drug through the fungal cell membrane, exerting better antifungal activity than control formulation. Thus, it can be put into conclusion that tolnaftate nail lacquer formulation exerts effective antifungal activity than control solution.

\section{References}

1. Akhtar N, Sharma H, Pathak K. Onychomycosis: potential of nail lacquers in transungual delivery of antifungals. Scientifica 2016; Article ID 1387936.

2. Roberts DT, Taylor WD, Boyle J. Guidelines for treatment of onychomycosis. Br J Dermatol 2003; 148: 402-10.

3. Westerberg DP, Voyack MJ. Onychomycosis: current trends in diagnosis and treatment. Amer Fam Phy 2013; 88: $762-70$

4. Shivakumar HN, Juluri A, Desai BG, Murthy SN. Ungual and transungual drug delivery. Drug Develop Ind Pharm 2012; 38: 901-11.

5. Firoz S, Sirisha MN, Rajalakshmi R. Transungual drug delivery system: a review. Int J Innov Drug Disc 2011; 1: 9-14.

6. Joshi M, Sharma V, Pathak K. Matrix based system of isotretinoin as nail lacquer to enhance transungal delivery across human nail plate. Int J Pharm 2015; 478: 268-77.

7. Kute SB, Saudagar RB. Formulation and evaluation of tolnaftate loaded topical emulgel. Inventi J 2014; 4: 14-29.

8. Jan S, Bora D, Bhise K. Preungual drug delivery systems of terbinafine hydrochloride nail lacquer. Asian J Pharm 2008; 2: 53-6.

9. Meghana G, Karri VVSNR, Talluri SV, Gunda R, Channareddy SR, Ganesh GNK. Formulation and evaluation of tolnaftate loaded topical liposomal gel for effective skin drug delivery to treat fungal diseases. J Chem Pharm Res 2014; 6: 856-66.

10. Nail polish (Nail enamel) - Specification, Bureau of Indian Standards, IS 9245, 1994; PCD 19: Cosmetics.

11. Jaiswal M, Kumar M, Pathak K. Zero order delivery of itraconazole via polymeric micelles incorporated in situ ocular gel for the management of fungal keratitis. Coll Surf B: Biointerf 2015;130: 23-30.

\section{Conclusion}

In the present study, a novel medicated nail lacquer based formulation of tolnaftate was successfully developed and tested for its effectiveness in enhancing the penetration across the bovine hoof and nail plate. Developed system adheres to the nail plate for longer period of time, providing sustained drug release. Thus, it can be concluded from this investigation that nail lacquer based formulation could proved to be fruitful in delivering antifungal drug effectively. These can be efficiently used in the management of onychomycosis.

\section{Conflict of interest}

Authors had declared no conflict of interest

12. Muzikova Z, Simscek P, Pospisil M, Sebor G. Density, viscosity and water phase stability of 1-butanol-gasoline blends. J Fuels 2014;1:1-7.

13. Rowe, R.C, Sheskry, P.J, Owen SC. Handbook of Pharmaceutical Excipients: 5th ed. Pharmaceutical press, London; 2006.

14. Sharma PP. Cosmetics- formulation, manufacturing and quality control, 4th ed. Vandana publications (India) Pvt. Ltd, Delhi; 2008.

15. Murdan S. Drug delivery to the nail following topical application. Int J Pharm 2002; 236: 1-26.

16. Chouhan P, Saini TR. Hydration of nail plate: Anovel screening model for transungual drug permeation enhancers. Int J Pharm 2012; 436: 179-82.

17. Nieto LN, Begona M, Otero-Espinar JF. Thermogelling hydrogels of cyclodextrin/poloxamer polypseudorotaxanes as aqueous-based nail lacquers: Application to the delivery of triamcinolone acetonide and ciclopirox olamine. Eur $\mathrm{J}$ Pharm Biopharm 20013; 83: 370-7.

18. Keshri L, Pathak K. Development of thermodynamically stable nanostructured lipid carrier system using central composite design for zero order permeation of econazole nitrate through epidermis. Pharm Dev Technol 2013; 18 634-44.

19. Hussan D, Choudhary SR, Sharma D, Bhandari V, Singh M. Transungual drug delivery-a novel approach of unique features. Indo Amer J Pharm Res 2013; 3: 4460-70.

20. Kumar PT, Narayana RP. Transungual drug delivery: a promising rote to treat nail disorders. Int J Pharm Res Rev 2013; 2: 22-33.

21. Rajendra VB, Baro A, Kumari A, Dhamecha DL, Lahoti SR, Shelke SD. Transungual drug delivery: an overview. J Appl Pharm Sci 2012; 2: 203-9. 
22. Murdan S. Erratum to Drug delivery to the nail following topical application. Int J Pharm 2002; 236: 1-26.

23. Mohorcic M, Torkar A, Friedrich J, Kristl J, Murdan S. An investigation into keratinolytic enzymes to enhance ungual drug delivery. Int J Pharm 2007; 332: 196-201.

24. Sharma PP. Cosmetics-formulation, manufacturing, and quality control, $4^{\text {th }}$ edition, Vandana publications (India), Pvt. Ltd., New Delhi.

25. Schlossman M. Techniques for evaluation of nail enamel. J Soc Cosm Chem 1981; 32: 43-52.

26. Piao ZZ, Lee KH, Kim DJ, Lee HG, Lee J, Oh KT, et al. Comparison of release- controlling efficiency of polymeric coating materials using matrix type casted films and diffusion controlled coated tablet. AAPS Pharm Sci Tech 2010;11: 630-6.
27. Hung SF, Hsiech CM, Chen CY, Wang YC, Ho HO, Sheu MT. Characterizations of plasticized polymeric film coatings for preparing multiple unit floating drug delivery systems with controlled release characteristics. PLoS One 2014; 9: e100321.

28. Lin SY, Chen KS, Run-Chu L. Organic esters of plasticizers affecting the water absorption, adhesive property, glass transition temperature and plasticizer permanence of eudragit acrylic films. J Controlled Release 2000; 68: 343-50.

29. Desai AS, Shripathy D, Shabaraya AR. Development and Optimization of Nail Lacquer Containing Fluconazole for Transungual Drug Delivery System. Amer J PharmaTech Res 2014; 4: 237-53. 